\title{
Cystic fibrosis pathogens survive for extended periods within cough-generated droplet nuclei
}

\author{
Michelle E Wood, ${ }^{1,2,3}$ Rebecca E Stockwell, ${ }^{1,3}$ Graham R Johnson, ${ }^{4}$ Kay A Ramsay, ${ }^{1,3}$ \\ Laura J Sherrard, ${ }^{1,5}$ Timothy J Kidd,${ }^{1,6,7}$ Joyce Cheney, ${ }^{8}$ Emma L Ballard, ${ }^{9}$ \\ Peter O'Rourke, ${ }^{9}$ Nassib Jabbour, ${ }^{4}$ Claire E Wainwright, ${ }^{3,7,8}{ }^{2}$ Luke D Knibbs, ${ }^{10}$ \\ Peter D Sly, ${ }^{3,7}$ Lidia Morawska, ${ }^{4}$ Scott C Bell ${ }^{1,2,3}$
}

\begin{abstract}
- Additional material is published online only. To view please visit the journal online (http://dx.doi.org/10.1136/ thoraxjnl-2018-211567)
\end{abstract}

For numbered affiliations see end of article.

\section{Correspondence to} Ms Michelle E Wood, Adult Cystic Fibrosis Centre, The Prince Charles Hospital, Brisbane, QLD 4032, Australia; michelle.wood2@health.qld. gov.au

Received 21 January 2018 Revised 9 March 2018 Accepted 19 March 2018 Published Online First 7 April 2018

\section{Check for updates}

To cite: Wood ME, Stockwell RE, Johnson GR, et al. Thorax 2019;74:87-90.

\section{ABSTRACT}

The airborne route is a potential pathway in the personto-person transmission of bacterial strains among cystic fibrosis (CF) populations. In this cross-sectional study, we investigate the physical properties and survival of common non-Pseudomonas aeruginosa CF pathogens generated during coughing. We conclude that Gramnegative bacteria and Staphylococcus aureus are aerosolised during coughing, can travel up to $4 \mathrm{~m}$ and remain viable within droplet nuclei for up to $45 \mathrm{~min}$. These results suggest that airborne person-to-person transmission is plausible for the CF pathogens we measured.

\section{INTRODUCTION}

Recurrent pulmonary infection characterises cystic fibrosis (CF). While Pseudomonas aeruginosa is generally the most prevalent respiratory pathogen, Staphylococcus aureus, Stenotrophomonas maltophilia, Achromobacter and Burkholderia species are common.

Studies have demonstrated genetically indistinguishable strains of $P$. aeruginosa,${ }^{1}{ }^{2}$ Burkholderia cepacia complex species ${ }^{3}$ and Mycobacterium abscessus ${ }^{4}$ both within and between CF centre populations. Environmental reservoirs are infrequently identified for these shared bacterial strains, suggesting possible cross-infection. The airborne route is a possible mode of person-to-person transmission of $P$. aeruginosa and $M$. abscessus, which can be aerosolised during coughing by people with CF and remain viable within droplet nuclei $\left(\leq 4.7 \mu \mathrm{m}\right.$ in size) for extended durations. ${ }^{45}$ The extent of airborne dissemination of other common CF pathogens is poorly understood.

We studied survival of CF pathogens (other than $P$. aeruginosa and M. abscessus) in the air over distance and duration and compared the results with the survival of $P$. aeruginosa during voluntary coughing. It was hypothesised that individuals with CF produce similar levels of droplet nuclei containing Gram-negative bacteria (GNB) and $S$. aureus during coughing, which can travel up to $4 \mathrm{~m}$ and remain viable for up to at $45 \mathrm{~min}$.

\section{METHODS}

Participants $\geq 14$ years, with CF were assigned to either GNB or $S$. aureus groups based on positive sputum microbiological results in the prior 2 years. On the testing day, spirometry was performed and sputum was collected.

The experimental equipment comprised of two validated, independent systems to study the distance travelled and survival duration of bacteria contained in aerosols generated during coughing. ${ }^{5}$ Participants completed five cough experiments; distance studies involved aerosol sampling at 2 and $4 \mathrm{~m}$, while the duration studies involved the ageing of cough aerosol samples for 5, 15 and 45 min prior to extraction. ${ }^{5}$ Aerosol sampling was undertaken through an Andersen Cascade Impactor and cough aerosol cultures were performed (see online Supplementary file 1 ).

Data were analysed using SPSS V.23. The experimental unit was organism. The total colony-forming unit (CFU) counts for sputum and aerosol plates were compared between GNB and $S$. aureus after $\log _{10}$ transformation for analysis and back-transformation to the geometric mean for reporting. Where the organism was detected in sputum samples, a Pearson's correlation examined correlations between sputum and total viable aerosol at $2 \mathrm{~m}$ for each of the GNB and $S$. aureus organisms detected. The $2 \mathrm{~m}$ distance was selected in accordance with the current infection control recommendations for separation between people with $\mathrm{CF}^{6}$ and correlation data for $P$. aeruginosa from our recent study was also reported as a comparison. ${ }^{7}$

\section{RESULTS \\ Population description}

Thirty participants (19 males (63.3\%)) with mean (SD) age 29.9 (10.4) years, FEV 61.9 (25.7) \% predicted and body mass index $23.6(4.5) \mathrm{kg} / \mathrm{m}^{2}$ were studied. Twelve participants had a history of GNB infection, 12 participants had pre-existing $S$. aureus infection and six participants harboured both a GNB and S. aureus; thereby 18 participants were assigned to each organism group (figure 1). One participant $(\mathrm{GNB})$ could not tolerate or complete the 15 and 45 min duration experiments.

\section{Sputum bacteriology}

Expectorated sputum samples were provided by 29/30 participants. Participants with negative or missing sputum cultures were excluded from the analysis. Of the 18 participants with previous GNB infection, 18 GNB organisms were identified in sputum from 15 participants (three participants harboured two different GNB species): S. maltophilia, $\mathrm{n}=7$; Achromobacter spp., $\mathrm{n}=5$; 


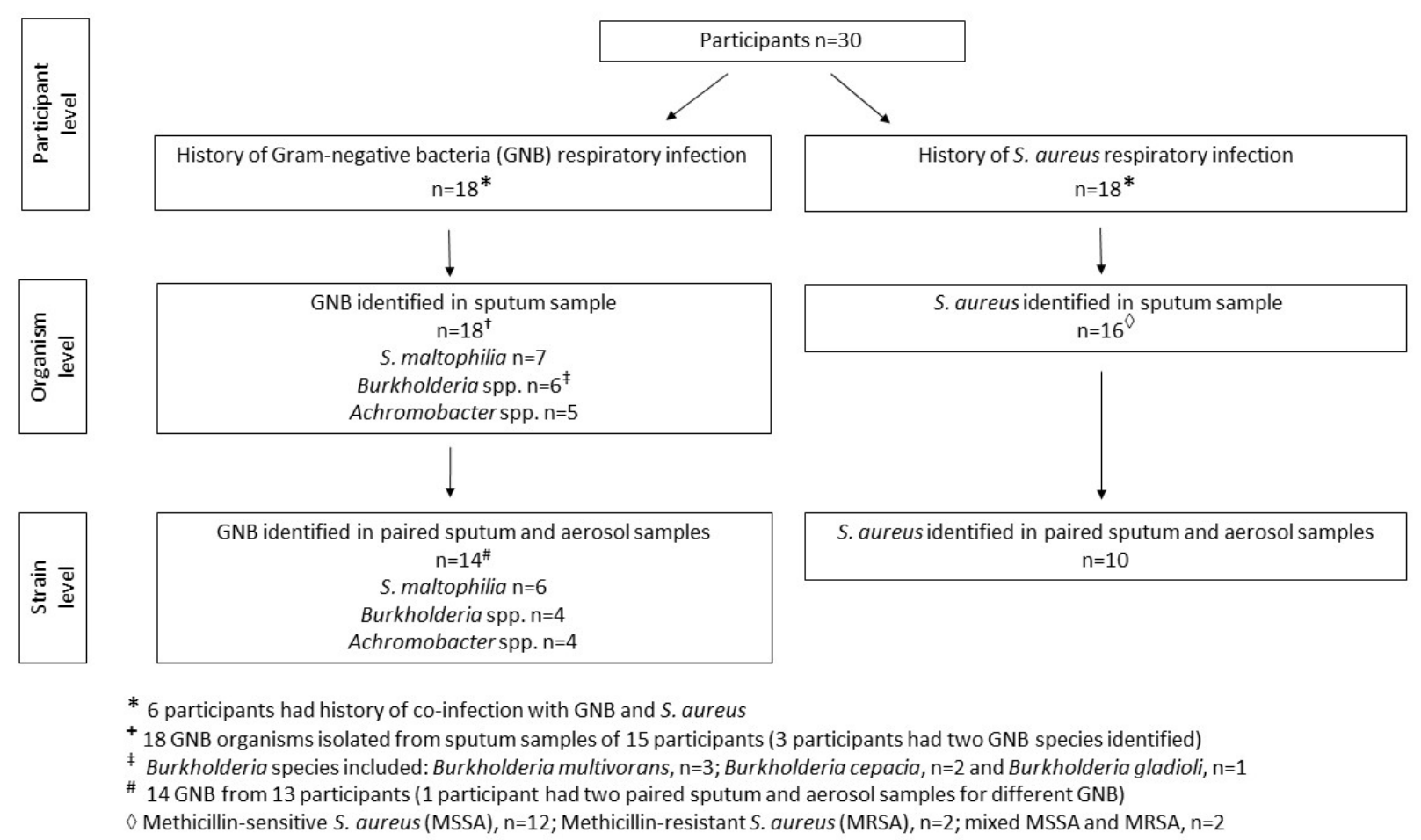

Figure 1 Flow chart of participant stratification and matched sputum/aerosol findings.

Burkholderia spp., $\mathrm{n}=6$ (figure 1). S. aureus was recovered from $16 / 18$ participants with history of infection (figure 1 ). The mean $(95 \% \mathrm{CI})$ sputum bacterial concentration $\left(\mathrm{CFU} / \mathrm{mL} \times 10^{6}\right)$ for the GNB group was 7.0 (95\% CI 1.6 to 31$)$ and for the $S$. aureus group, 1.3 (95\% CI 0.2 to 7.5$)(\mathrm{p}=0.13$; table 1$)$.

\section{Aerosol sampling}

During the cough experiments, at least one positive aerosol was detected for 15/18 (83\%) organisms in the GNB group and 10/16 $(63 \%)$ in the $S$. aureus group $(\mathrm{p}=0.25)$. Eleven out of $18(61 \%)$ GNB organisms were cultured at $4 \mathrm{~m}$ and $9 / 17$ (53\%) at $45 \mathrm{~min}$; whereas for the $S$. aureus group, 8/16 (50.0\%) had viable aerosol at $4 \mathrm{~m}$ and $4 / 16(25 \%)$ at $45 \mathrm{~min}$, with no significant difference in the number of bacterial CFUs between the groups at any distance or duration (table 1). The mean percentage of viable particles cultured in the droplet nuclei size range $(\leq 4.7 \mu \mathrm{m})$ was 66.5 (SD 26.1) for the GNB organism group and 58.2 (SD 26.0) for the $S$. aureus group $(\mathrm{p}=0.46)$.

\section{Sputum and aerosol bacterial typing}

Fourteen viable GNB cultures were detected in cough aerosols from 13 participants (figure 1) and each organism had an identical genotype identified in paired sputum (confirmed by multilocus sequence typing-derived from whole genome sequences) including: S. maltophilia $(\mathrm{n}=6)$; Achromobacter spp. $(\mathrm{n}=4)$ and Burkholderia spp. $(\mathrm{n}=4)$. Aerosolised bacteria were not

Table 1 Comparison of the sputum and aerosol concentrations between the GNB and S. aureus groups

\begin{tabular}{|c|c|c|c|c|c|}
\hline \multirow[b]{2}{*}{ Sputum parameter; mean* $(95 \% \mathrm{CI})$} & \multicolumn{4}{|c|}{ Stratified by organism/s identified in sputum } & \multirow[b]{2}{*}{$P$ values } \\
\hline & GNB, $n=18 \dagger$ & & Staphylococcus aureus, $\mathrm{n}=16$ & & \\
\hline Sputum bacterial concentration (CFU/mL $\left.\times 10^{6}\right)$ & $7.0(1.6$ to 31$)$ & & $1.3(0.2$ to 7.5$)$ & & 0.13 \\
\hline Aerosol parameter; mean* $(95 \% \mathrm{Cl})$ & $\mathrm{n} \ddagger$ & GNB aerosol (CFU) & $\mathrm{n} \ddagger$ & S. aureus aerosol (CFU) & P values \\
\hline \multicolumn{6}{|l|}{ Distance $(\mathrm{m})$} \\
\hline 2 & 14 & 11 (4 to 28$)$ & 9 & $5(2$ to 10$)$ & 0.22 \\
\hline 4 & 11 & $20(7$ to 50$)$ & 8 & 7 (2 to 23$)$ & 0.14 \\
\hline \multicolumn{6}{|l|}{ Duration (min) } \\
\hline 5 & 10 & 13 (4 to 38$)$ & 8 & 3 (1 to 8) & 0.062 \\
\hline $15 \S$ & 9 & 10 (3 to 32$)$ & 6 & $4(2$ to 7$)$ & 0.12 \\
\hline $45 \S$ & 9 & 12 (3 to 40$)$ & 4 & $4(1$ to 12$)$ & 0.10 \\
\hline
\end{tabular}

${ }^{*}$ Geometric mean.

†18 GNB organisms identified from the sputum of 15 participants (three participants had two GNB species detected).

$¥$ Target organisms identified in sputum that had a positive aerosol detected.

$\S 0$ ne GNB group participant did not complete the 15 and 45 min duration experiments.

$\mathrm{CFU} / \mathrm{mL}$, colony forming units per millilitre of sputum; GNB, Gram-negative bacteria. 
detected for five participants in the GNB group, including the participant who did not provide a sputum sample. Each participant had distinct strains of GNB species. Ten of 16 participants had $S$. aureus cultured from their paired sputum and aerosol samples (figure 1) and 8/10 had concordant genotypes. Isogenic strains were identified in the aerosol and sputum samples of the remaining two participants (as determined by single nucleotide polymorphism-based genotyping).

\section{CFU correlations at $2 \mathrm{~m}$}

Bacterial sputum and aerosol concentrations were correlated for GNB species $(\mathrm{r}=0.50, \mathrm{p}=0.035)$ and $S$. aureus $(\mathrm{r}=0.66$, $\mathrm{p}=0.005)$ compared with $\mathrm{r}=0.55(\mathrm{p}=0.005)$ for $P$. aeruginosa.

\section{DISCUSSION}

Cross-infection of CF pathogens remains a concern, with the airborne route considered a potential transmission pathway. ${ }^{4} 8$ This study demonstrates that GNB species and $S$. aureus commonly recovered from people with CF can be aerosolised during coughing, travel up to $4 \mathrm{~m}$ from source and survive within droplet nuclei for up to $45 \mathrm{~min}$, which is similar to airborne characteristics of $P$. aeruginosa and M. abscessus. ${ }^{45}$ The majority of viable particles were within the size range potentially capable of airborne dispersal and inhaled airway deposition.

Evidence demonstrating cross-infection of B. cepacia complex species and methicillin-resistant $S$. aureus is clearly established and possible for some Achromobacter spp. strains. ${ }^{369}$ With each of the organisms of interest investigated in the current study, routes of acquisition could also be related to healthcare contact. $^{6}{ }^{10}$ This study highlights the potential for person-toperson transmission of common CF bacterial pathogens via the airborne route. As found in our earlier cough aerosol studies with $P$. aeruginos $a^{57}$ an association between aerosol CFUs and sputum CFU concentrations for GNB and $S$. aureus has been demonstrated, suggesting those with a higher burden of microbial load in the sputum may pose a greater risk of airborne transmission. Taken together, these data provide further support for surgical mask wear to minimise potential cross-infection within CF healthcare facilities. ${ }^{7}$

Study limitations include that the infectious dose to cause bacterial infection in CF is unknown and it is not possible to quantify individual risk of transmission via the airborne route. Similarly, the implications for younger children remains undetermined and our findings may not be representative for all people with CF.

This study has demonstrated that common CF pathogens can be aerosolised during coughing and survive within droplet nuclei for extended durations, highlighting the importance of universal infection control practices for all people with CF.

\footnotetext{
Author affiliations

${ }^{1}$ Lung Bacteria Group, QIMR Berghofer Medical Research Institute, Herston, Queensland, Australia

${ }^{2}$ Adult Cystic Fibrosis Centre, The Prince Charles Hospital, Chermside, Queensland, Australia

${ }^{3}$ Faculty of Medicine, The University of Queensland, Brisbane, Queensland, Australia ${ }^{4}$ International Laboratory for Air Quality and Health, Queensland University of Technology, Brisbane, Queensland, Australia

${ }^{5}$ School of Pharmacy, Queen's University Belfast, Belfast, United Kingdom

${ }^{6}$ School of Chemistry and Molecular Biosciences, The University of Queensland,

Brisbane, Queensland, Australia

${ }^{7}$ Child Health Research Centre, The University of Queensland, South Brisbane,

Queensland, Australia

${ }^{8}$ Department of Respiratory and Sleep Medicine, Lady Cilento Children's Hospital, South Brisbane, Queensland, Australia

${ }^{9}$ Statistics Unit, QIMR Berghofer Medical Research Institute, Herston, Queensland,
}

Australia

${ }^{10}$ School of Public Health, The University of Queensland, Herston, Queensland, Australia

Acknowledgements We thank the participants from the CF Centres at the Lady Cilento Children's Hospital and The Prince Charles Hospital and gratefully acknowledge staff within the Pathology Queensland Central Laboratory and Australian Genome Research Facility for their assistance with bacterial genotyping and whole-genome sequencing. This publication made use of the Burkholderia cepacia complex Multi Locus Sequence Typing website (https://pubmlst.org/bcc/) developed by Keith Jolley and sited at the University of Oxford (Jolley and Maiden 2010, BMC Bioinformatics, 11:595). The development of this site has been funded by the Wellcome Trust.

Contributors GRJ, TJK, CEW, LDK, PDS, LM and SCB led the funding application and conceived the study design. MEW, JC and SCB contributed to subject recruitment. MEW, RES, GRJ and NJ conducted the studies and collected the participant data and samples. RES, KAR and LJS performed the microbiological analysis. TJK and KAR undertook the genotypic analyses for GNB and Pathology Queensland for Staphylococcus aureus. ELB and POR led the statistical analysis. MEW and SCB oversaw the overall study and wrote the manuscript, with input from all authors.

Funding The project was funded from grants from Cystic Fibrosis Foundation Therapeutics, USA (BELL14A0) and The Prince Charles Hospital Foundation (MS2014-20).

Competing interests During conduct of the study: SCB reports grants from Cystic Fibrosis Foundation Therapeutics, USA, and The Prince Charles Hospital Foundation and outside of the submitted work, travel support to attend conferences from Novartis and Gilead and meetings for clinical trials sponsored by Vertex, Abbvie, Raptor. LDK reports grants from the NHMRC during the conduct of the study. GRJ reports grants from Cystic Fibrosis Foundation Therapeutics, USA, and The Prince Charles Hospital Foundation during the conduct of the study. CEW reports outside of the submitted work: research grant from Novo Nordisk Pharmaceuticals; honorarium fees as speaker for Vertex, DKBmed; honorarium for consulting work (BMJ, Vertex), advisory board (Vertex); to present at conference (Novartis), attendance at meetings (University of Miami), Associate Editor duties (Thorax) and travel support to attend meetings for clinical trials sponsored by Vertex. CEW is Associate Editor Thorax and Associate Editor Respirology. MEW reports outside of submitted work: travel support to attend clinical trial meetings sponsored by Vertex and Galapagos.

Patient consent Detail has been removed from this case description/these case descriptions to ensure anonymity. The editors and reviewers have seen the detailed information available and are satisfied that the information backs up the case the authors are making.

Ethics approval The project was granted approval by the Children's Queensland Human Research Ethics Committee HREC/14/RCH/88 and The Prince Charles Hospital Research Governance Office SSA/14/TPCH/202. Participants provided written consent/assent

Provenance and peer review Not commissioned; externally peer reviewed. (C) Article author(s) (or their employer(s) unless otherwise stated in the text of the article) 2019. All rights reserved. No commercial use is permitted unless otherwise expressly granted.

\section{REFERENCES}

1 Kidd TJ, Soares Magalhães RJ, Paynter S, et al. The social network of cystic fibrosis centre care and shared Pseudomonas aeruginosa strain infection: a cross-sectional analysis. Lancet Respir Med 2015;3:640-50.

2 Scott FW, Pitt TL. Identification and characterization of transmissible Pseudomonas aeruginosa strains in cystic fibrosis patients in England and Wales. J Med Microbiol 2004;53(Pt 7):609-15.

3 Govan JR, Brown PH, Maddison J, et al. Evidence for transmission of Pseudomonas cepacia by social contact in cystic fibrosis. Lancet 1993;342:15-19.

4 Bryant JM, Grogono DM, Rodriguez-Rincon D, et al. Emergence and spread of a human-transmissible multidrug-resistant nontuberculous mycobacterium. Science 2016:354:751-7.

5 Knibbs LD, Johnson GR, Kidd TJ, et al. Viability of Pseudomonas aeruginosa in cough aerosols generated by persons with cystic fibrosis. Thorax 2014;69:740-5.

6 Saiman L, Siegel JD, LiPuma JJ, et al. Infection prevention and control guideline for cystic fibrosis: 2013 update. Infect Control Hosp Epidemiol 2014;35(Suppl 1):S1-S67.

7 Wood ME, Stockwell RE, Johnson GR, et al. Face masks and cough etiquette reduce the cough aerosol concentration of Pseudomonas aeruginosa in people with cystic fibrosis. Am J Respir Crit Care Med 2018;197:348-55

8 Jones AM, Govan JR, Doherty CJ, et al. Identification of airborne dissemination of epidemic multiresistant strains of Pseudomonas aeruginosa at a CF centre during a cross infection outbreak. Thorax 2003;58:525-7. 
9 Ridderberg W, Bendstrup KE, Olesen $\mathrm{HV}$, et al. Marked increase in incidence of Achromobacter xylosoxidans infections caused by sporadic acquisition from the environment. J Cyst Fibros 2011;10:466-9.
10 Muhlebach MS, Heltshe SL, Popowitch EB, et al. Multicenter observational study on factors and outcomes associated with various methicillin-resistant Staphylococcus aureus types in children with cystic fibrosis. Ann Am Thorac Soc 2015;12:864-71. 